\section{La expansión de la telenovela}

Nora Mazziotti

\section{La circulación internacional de} telenovelas

Es sabido que los géneros televisi-

— vos están en constante estado de redefinición. Mientras que la fórmula de los reality shows, que habían sido la gran novedad en los últimos años, parece ya no despertar el furor anterior, uno de los géneros más tradicionales y transitados de América Latina: la telenovela, no solo continúa siendo el producto con mayores posibilidades en la región, sino que la "descubren" programadores de todo el mundo.

En años recientes, la telenovela se expandió por numerosos mercados. Ingresó en países en los que nunca se habían emitido programas semejantes. Y en muchos casos, se han consolidado en las parrillas de programación. En el 2006 se celebran los 15 años de Discop, la feria de venta de productos televisivos de Europa del Este, uno de los mercados que ha tenido un crecimiento sorprendente en estos años.

En las últimas décadas la circulación trasnacional de productos televisivos adquirió un volumen creciente. La telenovela latinoamericana conquistó nuevos mercados por varias razones, que tienen que ver con esa transnacionalización. Entre ellas está el surgimiento del cable y del satélite, la desregulación de los canales públicos en Europa, la caída de la Unión Soviética, que alientan la aparición de nuevas señales privadas. Se produce junto al au- 
mento de señales el del número de horas de programación, por lo que se necesitan contenidos para llenar varias franjas horarias. Y además, las nuevas tecnologías permiten una calidad en los productos antes inexistente.

Las nuevas naciones de la ex Unión Soviética prácticamente carecían de industria televisiva, y las telenovelas latinoamericanas resultaron un sostén fundamental de la programación. En Rusia, la emisión exitosa de Los ricos también lloran, verdadero motor de la expansión de la industria latinoamericana, en 1992, llenaba el vacío de programación entre las transmisiones de las sesiones de la Cámara de Diputados. ${ }^{1}$

Explica Álvaro Cueva: "Los ricos también lloran llegó a ser una garantía de éxito tan grande que Televisa la regaló en algunos países para que, al verla, el público conociera la televisión mexicana, se enamorara de ella y pidiera más telenovelas". ${ }^{2}$

\section{Difusión, serialidad y programación local}

Vale la pena preguntarse cuáles son los motivos por los que se ha difundido tanto la telenovela.
Desde el lado de las audiencias, porque cuentan una historia de amor, tienen que ver con los sentimientos y las emociones, entretienen, generan un vínculo de empatía, gusta la pareja, la música, etcétera.

Desde el lado de la industria, por tres razones:

- Por su carácter seriado: entre 120 y 300 capítulos. A los programadores les resulta útil que un mismo título (si funciona bien) les resuelva una determinada franja horaria por cuatro, seis o más meses. No es necesario estar pensando cada mes o todas las semanas qué colocar.

- Porque es barata. Es mucho más costoso producirla que comprarla. Más adelante me referiré a los precios de venta.

- Además, recientemente la telenovela se afianzó también como una plataforma para generar o apoyar otros negocios, derivados del merchandising, que incluye CD musicales, DVD, realización de shows en vivo, publicación de revistas, etcétera.

Ahora bien, como ya se señalaba en 1992 en el informe de la Unesco sobre circulación de programas televisivos, las audiencias prefieren ver programa-

1 BALDWIN, Kate. "Montezuma's revenge: Reading Los ricos también lloran in Russia", en ALLEN, Robert C. (ed.). To be continued... Soap operas around the world. London \& New York, 1995.

2 CUEVA, Álvaro. "25 razones por 25 años", 2005. <http://www.alvarocueva.com>. 
ción local antes que extranjera. ${ }^{3}$ El contexto es el de una televisión global, aunque esto no significa que los contenidos sean totalmente homogéneos.

Pero no todos los países tienen capacidad para producir una programación local. Los nuevos mercados de la telenovela se abrieron en países empobrecidos, en los que las políticas neoliberales y las guerras generaron severas crisis económicas, por lo que no pudieron desarrollar una industria televisiva. En esos territorios tal vez resulta posible hacer programas informativos, talk shows, musicales y entretenimiento, pero la ficción es lo más costoso.

Las principales dificultades en producir telenovelas o seriales son económicas. Aunque también tiene un peso importante la cuestión cultural o las prácticas laborales, ya que en muchos lugares los técnicos de TV no están acostumbrados a producir una hora de programación en una jornada laboral. Hay un desconocimiento del know how en lo que hace a la escritura de libretos, producción, dirección, actuación. El ritmo de escritura televisiva, el timing de actuación que requiere el melodrama, el grabar un libro abierto y que se escribe mientras está en el aire, es algo que en Latinoamérica se maneja sin problemas porque se practica desde los inicios de la televisión.
Esa dificultad en producir y el desconocimiento del género que tienen muchos países hace que el producto latinoamericano aún no haya alcanzado un límite en lo que se refiere a expansión territorial.

Sin embargo, varios mercados que eran compradores hoy producen sus propias novelas. No es que hayan dejado de comprarlas, sino que también quieren aprender a producirlas. Ocurre en algunos países del este europeo, como Rumania, Eslovenia, Serbia, Croacia o Rusia. A pesar de que esos nuevos productores todavía realizan escasos títulos al año, y algunos no lo hacen con continuidad, se debe abandonar cualquier triunfalismo sobre la expansión latinoamericana. La telenovela se globalizó, pero eso no significa que siempre se fabrique en América Latina.

\section{Compra y venta de formatos}

Paralelamente, aparecen nuevas formas de comercialización, como puede ser la venta del formato, en lugar del producto terminado. Vender el formato significa vender el concepto del programa, los libros, la "Biblia" de producción, participar en el casting, asesorar en distintas etapas de la producción, etcétera.

3 LARSEN, Peter. Importación/ exportación: Circulación internacional de programas televisados de ficción. París: Unesco, Estudios y documentos de comunicación de masas 104, 1992. 
Años atrás, la venta del formato se daba fundamentalmente en los programas de juego o entretenimiento y hoy alcanza también a la ficción. Esto se relaciona con lo dicho más arriba, el hecho de que las audiencias prefieren la programación local.

Esa es la razón por la que se producen, en un movimiento de glocalización, distintas versiones locales de sitcoms norteamericanas (La niñera se hizo en Argentina y en Colombia) o la novela humorística argentina Los Roldán se emite como Los Reyes en Colombia y Los Sánchez en México. Para una industria con dificultades, como la argentina, la venta de formatos permite una expansión mayor al colocar un producto en mercados de difícil acceso, como México, por ejemplo, donde el noventa por ciento de la programación exhibida es realizada localmente.

El caso de la compra del formato de Amas de casa desesperadas es novedoso, ya que el grupo Clarín acordó con Disney grabar en Buenos Aires, con la productora argentina Pol-ka, versiones de la serie para Argentina, Colombia, Ecuador y Brasil. "Cada nueva versión seguirá el formato y los guiones de la versión estadounidense, pero adaptada para cada país con sus propios elencos y sabores locales", se informa. ${ }^{4}$

\section{La producción y distribución de telenovelas}

Las telenovelas se han convertido en el único producto de reconocimiento internacional de la televisión latinoamericana. Para comprender el negocio es necesario comenzar por conocer la capacidad de producción y distribución de las principales compañías.

Producir un capítulo de una hora ocupa una jornada de trabajo que puede ser de 12 horas a más. Los precios varían desde los 20 mil dólares en la Argentina (a causa de la devaluación y la crisis del 2001) a los 150 mil dólares de las superproducciones de la Globo, como El clon. Telemundo está invirtiendo aún más en sus producciones.

Las principales empresas productoras y distribuidoras en el negocio de la telenovela son: Televisa, TV Azteca, Argos (México); TV Globo, Rede Record (Brasil); Caracol TV, RCN, RTI, Invento (Colombia); Venevisión; RCTV (Venezuela); Pol-ka, Telefé Internacional, Cris Morena Group, (Argentina); Telemundo, Fonovideo, Tepuy (Estados Unidos); Dori Media Group (Israel-Argentina). En las páginas web de las respectivas compañías hay información sobre ellas. Entre todas (y sumando también las de países como Chile y Perú) se fabrican al año 40 títulos te telenovelas.

4 <http://www.tvlatina.net> (2006). 


\section{Los números de la circulación de telenovelas}

Hay datos que ilustran sobre la circulación transnacional de telenovelas. El número total de espectadores de telenovela en el mundo se calcula en 2 mil millones de personas. Se hacen doblajes o subtitulados en 50 idiomas o dialectos. Según la empresa europea Médiametrie, que elabora el ranking de los 10 programas más vistos en 72 territorios, la novela creció un 35 por ciento entre 1999 y el 2002. En Latinoamérica creció del 24 al 42 por ciento.

A fines del 2000, por día se exhibían en pantallas de todo el mundo 200 horas producidas por Televisa, 100 de Globo y 45 de TV Azteca. ${ }^{5}$

También existen señales dedicadas exclusivamente a transmitir telenovelas. Estas son, hasta el momento:

- Romántica, asentada en Polonia, llega a 5.700.000 hogares en 26 países, y transmite más de mil horas al año, abastecida exclusivamente con novelas de Venevisión. ${ }^{6}$

- En Israel hay dos señales que se transmiten por cable y por satélite dedicadas al género, pertenecientes a Dori Media Group: Viva y Viva
Platino. Extendidas por 42 países de Europa del Este y Medio Oriente, emiten productos de varios países. Viva adquiere dos mil nuevas horas por año, y desde el 2002 coproduce títulos en Argentina.

- El Dori Media Group lanzará en el 2006 en Indonesia el canal Visión 2, también dedicado al género.

- Se anunció en el 2005 que Telefé tendría un canal en Malasia, Telefé International Telenovelas Channel.

- Fox Life va a dedicar un segmento a telenovelas: el prime time diurno.

- Televisa tiene dos señales de satélite: TL y TL Europa, en los que emite programación propia.

Entre 1970 y 1995, TV Globo de Brasil ha ido incrementando su cantidad de títulos exportados. En los últimos diez años Globo ha vendido más de 200 novelas, miniseries y series a los principales mercados de Europa del Este. ${ }^{7}$

Yo soy Betty, la fea, que fue portada del Washington Post y del New York Times, es uno de los casos más significativos de venta de la versión original como del formato. Este fue vendido a Televisa, que la emite en México bajo el nombre de La fea más bella; a Sony

\footnotetext{
5 VILlANUEVA, Mario. "Minas de oro. El melodrama, la telenovela en América y su nacimiento en MéxicO", 2000.<http://www.operamundi.com.mx/2000/01>.

6 "Cine y televisión on line". <http://www.dorimediagroup.com>.

$7 \quad<$ http://www.tvlatina.net $>$.
} 
Pictures Television International (SPTI) y Fremantle Media, que vendieron su versión en Alemania (titulada Verliebt in Berlin y que fue la primera telenovela producida en ese país), Francia, Italia, España, Rusia, India, Indonesia, Malasia, Filipinas, Japón y China, y recientemente a la cadena ABC, que hará su propia versión para el mercado estadounidense. Sony la adaptó para India y Rusia. Su versión animada, Betty Toons, fue vendida a Cartoon Network (Turner).

\section{Negocios y ganancias}

El hecho de que las empresas tengan oficinas de venta internacional en Miami o en Los Ángeles, o que en la segunda mitad de la década de 1990 se institucionalizara la realización de ferias de venta y exhibición de programación televisiva, son muestras de que el volumen de este negocio creció y se globalizó. En estas ferias, que se reparten a lo largo del año y del mundo, participan productoras y compradoras de programación televisiva.

Los datos sobre cifras de venta son de difícil acceso y verificación, al igual que la cantidad de países que exhiben algún título. Por ejemplo, la revista
TVmas Magazine calculaba en el 2001 que la telenovela generaba un negocio de "130 millones de dólares al año, de los cuales un 55 por ciento a 60 por ciento va a las arcas de Televisa". ${ }^{8}$

Daniel Mato expone cifras mayores:

Según estimaciones confiables, en 1997 el total de exportaciones de telenovela de Protele (la distribuidora internacional de Televisa de México, actualmente se denomina Televisa Estudios) y de TV Globo de Brasil representó aproximadamente unos 100 millones de dólares para cada una de ellas; el de RCN (Radio Cadena Nacional) de Colombia; Venevisión Internacional, distribuidora de Venevisión de Venezuela, y Artear y Telefé de Argentina representó aproximadamente unos 15 millones para cada una de ellas. ${ }^{?}$

Hasta el 2000, Café con aroma de mujer había sido vendida en 54 países y generado ganancias por 8 millones de dólares, y en el 2001 llegó a los 77 países (tvmasmagazine, 2001). En el año 2000, para Venezuela la telenovela representó un negocio de 15 millones de dólares; de 50 millones para México y de 35 millones para Brasil (dinero.com, 2000). Las dos cadenas de Colombia, Caracol y RCN, en el 2001 ganaron 12 millones de dólares la prime-

8 <http://www.tvmasmagazine.com> (2001).

9 MATO, Daniel. "Telenovelas: Trasnacionalización de la industria y transformaciones del género", en GARCÍA CANCLINI, Néstor y Carlos MONETA (coords.). Las industrias culturales en la integración latinoamericana. Buenos Aires: Eudeba/Sela, 1999, pp. 229-257. 
ra y 13,5 millones la segunda (Radio Enlace, 2001). Mientras que TV Azteca vendió por 13 millones de dólares en el $2000 .{ }^{10}$

En Colombia, de acuerdo con datos suministrados por RCN Televisión, el crecimiento en las ventas internacionales es notorio. Se pasó de 4.000 millones de pesos en 1999 a 43 mil millones en el 2002. El mayor mercado está en Estados Unidos (45 por ciento), seguido por México (11 por ciento). En el caso de Caracol Televisión, en los primeros seis meses del 2004 sumaron 25 mil millones de pesos (El Tiempo, 2004).

A pesar de que la venta internacional de telenovela es el principal rubro de exportación de las empresas latinoamericanas: alrededor del 70 y 80 por ciento de sus ventas internacionales, los ingresos más altos provienen del mercado local, debido a la inversión publicitaria. ${ }^{11}$ Porque en las novelas sigue siendo prioritario el éxito local, hasta el momento continúan produciéndose orientadas a la repercusión en el país de origen.

\section{Precios de venta}

El precio es otro de los datos que se deben tomar en cuenta en el estudio del negocio de la telenovela. El valor de venta por capítulo no es uniforme, sino que entran en juego varios elementos. Ellos son: el éxito que obtuviera la novela en su país de origen, la zona geográfica donde está ubicado y el alcance regional del canal comprador, la cantidad de títulos que adquiere y el valor de la torta publicitaria en ese país.

Esto hace que haya enormes diferencias, ya que mientras España paga entre 7 y 10.000 dólares por capítulo de una hora de duración, y los canales hispanoparlantes de Estados Unidos entre 2.500 y 5.000 dólares, República Dominicana solo abona de 100 a 200 dólares. ${ }^{12}$ Y si bien no se desprecia la venta en ningún mercado, el objetivo de las empresas son los canales estadounidenses y de Europa occidental. Los valores no son estables: "Algunos precios tienden a bajar por determinada situación económica (...) hay otros que tienden a subir porque sube el poder adquisitivo de un territorio o

10 <http://www.tvmasmagazine.com> (2001).

11 MATO, Daniel. "Transnacionalización de la industria de la telenovela, referencias territoriales y producción de mercados y representaciones de identidades transnacionales", en LACARRIEU, Mónica y Marcelo ÁLVAREZ (comps.). Una cartografía de los procesos culturales contemporáneos. Buenos Aires: Ciccus-la Crujía, 2002.

12 <http://www.tvmasmagazine.com> (2001); MATO, Daniel. "Transnacionalización de la industria de la telenovela, referencias territoriales y producción de mercados y representaciones de identidades transnacionales". Op. cit. 
crece su mercado publicitario" opina Silvana D'Angelo, de Telefé Internacional. ${ }^{13}$

\section{Los consumos. Negocios derivados y educación no formal}

El hecho de que se exhiban en tantas y tan diversas pantallas poco dice de su consumo y de su repercusión. A pesar de que en algunos lugares se exhiban en horarios marginales, o en señales de escasa penetración o alcance, el hecho de que en pocos años se hayan convertido en el principal producto televisivo latinoamericano de circulación transnacional, es relevante.

Y a esto se deben agregar las maneras en que la telenovela apoya el desarrollo de la industria de la música latina, a través de sus bandas de sonido o interpretadas por los propios protagonistas.

Actualmente, uno de los ingredientes infaltables en las tramas de las novelas juveniles es la formación de un grupo musical, que luego realiza giras con actuaciones en los países donde la novela fue emitida y graban discos compactos. Sucedió con Rebelde way y también con su versión mexicana $R e$ belde. La novela es también, y cada vez en mayor medida, una plataforma para nuevos negocios.

Sin que existan estudios fehacientes, en Brasil es sabido que la telenovela fomenta el turismo. Los ejecutivos de la TV Globo lo conocen desde tiempo atrás, cuando promocionan Río de Janeiro colocando imágenes de la playa o del Pan de Azúcar en las presentaciones de muchas novelas. En los años noventa, el exotismo de Pantanal generó viajes hacia esa zona del Matto Grosso. Recientemente, a partir de El clon, en Portugal se difundieron las compras de viajes hacia Marruecos.

En internet, la página de turismo Babia tropical, de Brasil, en la presentación del pueblo de Canes, menciona: "Hace poco la Red Globo rodó aquí la famosa telenovela Porto dos Milagros, así Canes logró una considerable popularidad en todo Brasil; gracias a esto vienen turistas a ver el lugar de los acontecimientos y la conocida Iglesia Azul, donde los protagonistas se casaron felizmente". ${ }^{14}$

En Israel, y a raíz del comentado éxito de las telenovelas, el español ha logrado ser, después del inglés, la lengua más hablada, y con gran aceptación entre los jóvenes. Un caso interesante de aprendizaje informal lo cons-

13 SÁNCHEZ, Lorena. "Entrevista a Silvana D'Angelo". Tram(p)as de la comunicación y la cultura 39. Facultad de Periodismo y Comunicación, UNLP, setiembre del 2005.

14 <http://www.bahiatropical.com.br>. 
tituye la lección diaria de español que emite el canal Viva, producido en cooperación con la sede de Tel Aviv del Instituto Cervantes. La lección tiene el formato de telenovela, una duración de 30 minutos, y está protagonizada por un actor argentino. Asimismo, viajar a América Latina es una nueva experiencia para jóvenes israelíes, que al finalizar el servicio militar vienen COmo mochileros a nuestro continente, comentan profesores de ese instituto. ${ }^{15}$

\section{La audiencia se hace visible}

Aunque para las empresas los espectadores se miden en puntos de rating, la problemática de las audiencias ha tenido un extenso desarrollo en el campo de los estudios universitarios, que pocas veces se han puesto en contacto con la industria. Las metodologías pueden diferir, pero el interés es el mismo: los públicos. Para los estudios de comunicación y cultura, las formas en que se ven los programas es de suma importancia. La interpretación está estrechamente relacionada con negociaciones, préstamos entre culturas, construcción de sentido, y todo esto incide en la conformación de las identidades y la vivencia de las propias subjetividades.

En este apartado me quiero referir a dos fenómenos que de manera diversa ponen en escena a las audiencias: los modos en que los espectadores se hacen visibles, de manera real o virtual.

El primero tiene lugar con las giras internacionales que realizan los protagonistas de las novelas exitosas, las formas en que son aclamadas y agasajadas en lugares remotos y con culturas diferentes.

Ya en 1992 Verónica Castro había sido recibida en Moscú con honores correspondientes a jefe de estado, a causa del furor que desató en Rusia la emisión de Los ricos también lloran, y la tendencia continuó. Más recientemente, Leticia Calderón fue rodeada de una multitud que coreaba "Esmeralda, Esmeralda", en Eslovenia, donde en pocos años se emitieron 50 telenovelas, luego de la exhibición de la novela de ese título. Algo semejante ocurrió con Coraima Torres y Osvaldo Dorios, protagonistas de Kassandra en Macedonia. Fue inmenso el éxito de Thalía en Filipinas, a quien también se le dio trato protocolar correspondiente a jefe de Estado. Y está el recibimiento a Natalia Oreiro y el éxito de ventas de sus discos compactos en Israel, Polonia, República Checa y Hungría. Esta actriz protagonizó en el 2005 una miniserie en Rusia, allí donde el episodio final de Muñeca brava se transmitió con pantallas gigantes en la calle y verdaderas

$15<$ http://www.tvlatina.net> 
"bailantas". Estas referencias no son solo anecdóticas o curiosas sino que resultan significativas para ser pensadas desde una óptica de globalización de los ídolos y de los consumos culturales, y de la creciente interculturalidad mediática.

El otro fenómeno es la existencia de páginas y de foros de opinión sobre telenovelas a que ha dado pie la expansión de internet. Si bien las páginas oficiales de un título o de un/a protagonista están en castellano y en varias lenguas diferentes, los foros de fans están escritos predominantemente en castellano, revirtiendo la hegemonía del inglés en internet. Foristas de diversas naciones dialogan, se cuentan capítulos, se pasan informaciones, se explican modismos, colocan información periodística, escriben notas y también sus propias críticas y novelas, las foronovelas. Y dan lugar asimismo a discusiones y bromas.

Internet contribuyó fuertemente a que la charla sobre novelas tenga lugar no solo en la casa, en la escuela o en el trabajo, sino que una espectadora de Rumania chatee con una mexicana sobre su galán favorito. En los foros, cada día más desarrollados, se encuen- tran desde saludos, que solo implican un contacto, a espectadores/as con un afinado y minucioso conocimiento de los títulos y de la historia del género, o coleccionistas de videos y DVD. ${ }^{16}$

Constituyen una fuente de estudio indirecto de recepción del género, que habla de la conformación de comunidades interpretativas virtuales, cuya cohesión y formación se sustenta a partir de una mediatización determinada -una telenovela o sus intérpretesque traspasa fronteras territoriales y lingüísticas.

Como dice Román Gubern:

En momentos en que las sociedades occidentales están viviendo una acelerada segmentación calificada de 'multicultural', las comunidades virtuales contribuyen a la tribalización de la sociedad posindustrial, parcelándola en tribus electrónicas diferenciadas por sus gustos y aficiones y basadas en el refuerzo mutuo de una identiddad específica. ${ }^{17}$

Los ejemplos citados -ver a los artistas en vivo y los foros en Inter.netconstituyen fenómenos de multiculturalismo y de interculturalidad, en el sentido que le da a estos conceptos

16 BORDA, Libertad. "Audiencias en la red: De la etnografía a los foros". Ponencia leída en el Encuentro Argentino de Carreras de Comunicación Social, Facultad de Ciencias Sociales, Universidad Nacional del Centro de la Provincia de Buenos Aires, Olavarría, 3-5 de octubre del 2002; BENASSINI, Claudia. "Comunidades virtuales, ¿espacios de convivencia pacífica?". Diá-logos de la comunicación 59-60. Octubre del 2000.

17 GUBERN, Román. El eros electrónico. Madrid: Taurus, 2000. 
Rodrigo Alsina: "El multiculturalismo [es] la ideología que propugna la coexistencia de distintas culturas en un mismo espacio real, mediático o virtual; mientras que la interculturalidad sería las relaciones que se dan entre las mismas". 18

A pesar de sus diferencias, ambas manifestaciones, que conjugan formas de comunicación interpersonal -el cara a cara con otros fans y hasta con los artistas en un estadio o en una sala teatral- o el virtual vía internet, las originan textos que en gran medida expresan valores o prohibiciones que poco tienen que ver con la vida cotidiana de las sociedades actuales, que pueden ser considerados anacrónicos, pero que también ponen en escena valores como la solidaridad, el afecto, la amistad o la justicia.

\section{"Todos quieren con la telenovela"}

La telenovela dejó de ser esa cosa que de tan familiar y doméstica nadie la tomaba en serio, dejó de ser un objeto despreciado, perdió su bastardía. Parodiando el título colombiano, hoy se puede decir: Todos quieren con la telenovela.
La quieren en la industria, cuya presión para convertirla en "un mero objeto de consumo", según la expresión de Guillermo Orozco, si bien estuvo presente desde sus inicios (y no solo en la telenovela, sino en todos los productos masivos) es hoy más fuerte que nunca. ${ }^{19}$

La quieren porque puede darles grandes ganancias, para hacerla punto de despegue de nuevos e importantes negocios. Ya los ha generado, pero puede dar más. La telenovela es una vidriera donde todo puede estar en venta, todo puede ser esponsorizado: los peinados, la ropa, los accesorios, el maquillaje, el lápiz de labios que saca del monedero una actriz o las cremas que usa, la marca de los anteojos, de los autos que aparecen, las bebidas que toman, etcétera.

La quieren los distribuidores de programación, los programadores de los canales, los actores y actrices, los diseñadores de estrategias de marketing; la industria fonográfica, las revistas de espectáculo.

La quieren las ONG dedicadas al desarrollo social, la promoción humana y los derechos civiles; así como los

18 RODRIGO ALSINA, Miquel. La comunicación intercultural. Barcelona: Anthropos, 1999.

19 OROZCO GÓMEZ, Guillermo. “¿De una expresión cultural a un mero objeto de consumo? Un itinerario de la telenovela en Hispanoamérica". Ponencia leída en el seminario "Hacia un estudio de la cultura popular en la Península Ibérica: una aproximación comparada”. Área de Teoría de la Literatura y Literatura comparada. Santiago de Compostela, Galicia, 2005. 
organismos de salud y de educación, porque saben de su capacidad para hablar a las audiencias, hacer tomar conciencia y para instalar una agenda social. Porque han constatado que apenas se menciona una enfermedad, un maltrato, un hecho de violencia, los espectadores aprenden a cuidarse o se informan a través de la telenovela.

La quieren las audiencias sedientas de historias, que le prestan sus horas libres, sus ratos con los hijos. Porque les gusta, les divierte, o porque no saben qué otra cosa ver. Porque después la pueden comentar con los amigos, en la peluquería o en el colegio; porque pueden llorar a gusto, con un beso, una confesión, una muerte..., o reírse de lo mala que es esa actriz.

No es fácil pensar qué caminos puede tomar la telenovela, hacia qué rumbos se dirigirá. ¿Podrá la telenovela mantener el equilibrio entre cultura y negocio? ¿Seguirá diciéndonos algo o se convertirá nada más que en un pretexto para vender algún producto? ¿Es posible que se transforme en un gran infomercial? ¿Qué queda de nuestro producto latinoamericano, ahora que la hacen con capitales norteamericanos y para los residentes en Estados Unidos?

No es que piense que la novela va a existir por siempre. Los géneros se transforman, y tal vez estemos en uno de los mayores momentos de inflexión, porque las posibilidades de que estalle en pedazos, se vacíe de conte- nido y no emocione más son muchas.

Pero siempre van a existir relatos en los que nos podamos mirar, con los que nos podamos identificar. Eso es parte de la cultura. La historia continúa, así que hay que ver los próximos capítulos.

\section{Bibliografía}

ADRIANZÉN HERRÁN, Eduardo. Las telenovelas: Cómo son, cómo se escriben. Lima: Pontificia Universidad Católica del Perú, 2001.

BALDWIN, Kate. "Montezuma's revenge: Reading Los ricos también lloran in Russia", en ALLEN, Robert C. (ed.). To be continued... Soap operas around the world. London \& New York, 1995.

BENASSINI, Claudia. "Comunidades virtuales, ¿espacios de convivencia pacífica?". Diá-logos de la comunicación 59-60. Octubre, 2000, pp. 208-224.

BERBENNI, Stefani. "Brasile/ Viaggio nella fabrica dei telesogni", 2002. <http://www.mondadori. com/panorama/area $>$.

BORDA, Libertad. "Audiencias en la red: De la etnografía a los foros". Ponencia leída en el Encuentro Argentino de Carreras de Comunicación Social, Facultad de Ciencias Sociales, Universidad Nacional del Centro de la Provincia de Buenos Aires, Olavarría, 3-5 de octubre del 2002. 
CUEVA, Álvaro."25 razones por 25 años", 2005. <http://www.alvarocueva.com>.

_- Sangre de mi sangre. Verdades y mentiras de las telenovelas en América Latina. México: Plaza y Janés, 2001.

Diario La Reforma. México, 27 de noviembre del 2001.

GUBERN, Román. El eros electrónico. Madrid: Taurus, 2000. "Llamado a escena". Dinero, 105. 7 de abril del 2000. [en línea]. <http://www.campus.oei. org/n4010.htm>.

LARSEN, Peter. Importación/exportación: Circulación internacional de programas televisados de ficción. París: Unesco, Estudios y documentos de comunicación de masas 104, 1992.

MATO, Daniel. "Trasnacionalización de la industria de la telenovela, referencias territoriales y producción de mercados y representaciones de identidades transnacionales", en LACARRIEU, Mónica y Marcelo ÁLVAREZ (comp.). Una cartografía de los procesos culturales contemporáneos. Buenos Aires: Ciccus-la Crujía, 2002.

—. "Telenovelas: trasnacionalización de la industria y transformaciones del género", en GARCÍA CANCLINI, Néstor y Carlos MONETA (coords.). Las industrias culturales en la integración lati- noamericana. Buenos Aires: Eudeba/Sela, 1999.

MAZZIOTTI, Nora. La industria de la telenovela. Buenos Aires: Paidós, 1996.

OROZCO GÓMEZ, Guillermo. “¿De una expresión cultural a un mero objeto de consumo? Un itinerario de la telenovela en Hispanoamérica". Ponencia leída en el seminario "Hacia un estudio de la cultura popular en la Península Ibérica: una aproximación comparada". Área de Teoría de la Literatura y Literatura comparada. Santiago de Compostela, Galicia, 2005.

ORTIZ DE URBINA, Araceli y Asbel LÓPEZ. "Un mundo de telenovelas". El Correo de la Unesco (unesco.org/courrir/1999_05).

RODRIGO ALSINA, Miquel. La comunicación intercultural. Barcelona: Anthropos, 1999.

SÁNCHEZ, Lorena. "Entrevista a Silvana D'Angelo". Tram(p)as de la comunicación y la cultura 39. Facultad de Periodismo y Comunicación, UNLP, setiembre del 2005.

SORROSA A., Raúl. "Telenovela Latinoamericana en Europa del Este". Chasqui 78, 2001.

VILLANUEVA, Mario. "Minas de oro. El melodrama, la telenovela en América y su nacimiento en México". <http://www.operamundi.com.mx/2000/01>. 


\section{Páginas web consultadas}

$<$ http://www.bahiatropical.com.br $>$

$<$ http://www.cineytelevisiónonline. com>

$<$ http://www.dinero.com/larevista $>$

$<$ http://www.dorimediagroup.com $>$

$<$ http://www.producción\& distribucion.com>

$<$ http://www.proexport.com>

$<$ http://www.rinconlatino.com $>$

$<$ http://www.serials.ru $>$

$<$ http://www.tvinsite.com $>$

$<$ http://www.tvlatina.net>

$<$ http://www.tvmasmagazine.com>

$<$ http://www.zonalatina.com> 